\begin{tabular}{|c|c|}
\hline & Asian Social Work Journal (ASWJ) \\
\hline $\begin{array}{c}\text { ASIAN SOCIAL WORK } \\
\text { JOURAL } \\
\text { (ASW) }\end{array}$ & Volume 3, Issue 3, July 2018 \\
& e-ISSN : 0128-1577 \\
& Journal home page: \\
& www.msocialwork.com \\
\hline
\end{tabular}

\title{
Contextual Social Interaction and Persuasive Strategy: Vital Facets of Older Adults' Interpersonal Relationship in Institutional Residence
}

\author{
Endah Dwi Winarni ${ }^{1}$ \\ 1Bandung College of Social Welfare
}

Corrrespondence: Endah Dwi Winarni (endah_dwiwinarni@yahoo.co.id)

\begin{abstract}
This study discusses the dynamic of older adults' interpersonal relationship in institutional residence. Several similar studies tended to analyze benefits of interpersonal relationship for older adults in institutional residence, types of social interaction between older adults in institutional residence, and common conversations between older adults in institutional residence. Those studies did not explore the ways to stimulate associative social interaction of older adults in institutional residence. Whereas, those ways are meaningful due to both older adults' body and mental functions have degenerated, so it makes them vulnerable to interact. Therefore, this study aims to fill that lack. This study argues the older adults' interpersonal relationship in institutional residence should be elaborated by contextual social interaction and persuasive strategy complementarily. This study uses a qualitative approach and conducted a case study at Jiwa Baru social protection residence, Garut, Indonesia. The finding is showed there are three context that form social interaction of older adults in institutional residence, namely personal instruments, structure, and culture; then, by understanding the process of social interaction was formed, can be formulized persuasive strategy to stimulate associative social interaction of older adults in institutional residence, e.g, persuaded by a closest friend, provide both a suitable assistance and care, create an interactive culture, and build a sense of community.
\end{abstract}

Key words: older adults, interpersonal relationship, social interaction, persuasive strategy

\section{Introduction}

The amount of older adult population in Indonesia has been increasing steadily by the year. In 2017, the amount of older adult population in Indonesia was 23,66 million people, which had been increasing nearly 3,4 million from the previous amount in 2014 (Central Bureau of Statistics of Indonesia, 2017). Furthermore, based on population projection data, it was predicted the amount of older adult population in Indonesia would continue to increase, e.g., 27,08 million in 2020, 33,69 million in 2025, 40,95 million in 2030, and 48,19 million in 2035 (Ministry of Health of Indonesia, 2017). The lot of older adult people in a country indicates the population age structure in a country is change into the older adults period. It was predicted that Indonesia would get into the older adults period in 2020, i.e. $10 \%$ of Indonesia's population would be aged 60 years or older (Ministry of Health of Indonesia, 2017). This situation has social-economy impacts to a familiy, a community, or a country. The impacts can be represent in a macro way by the increase of age dependecy ratio. In Indonesia, the age dependency ratio in 2017 was 14,02 , it was meant every 100 people of working age population had to bear the economic burden around 14 older adults (Central Bureau of Statistics of Indonesia, 2017). 
Regarding to these issues, the enhancement of older adults' well-being has been crucial for Indonesia, including their quality of interpersonal relationship in institutional residence. Interpersonal relationship is a signifier for both a deep and a solid social relation between two subjects or more (Berscheid, 1999). In practical way, interpersonal relationship is cultivated because social interaction have happened (Berscheid, 1999). As for social interaction is acts or contacts between subjects with motives and purposes (Blumer, 1969). Social interaction is different with communication, actually it is contain communication - which means the process of symbolic exchange between subjects to symbolize meaning (Blumer, 1969). Exploring older adults' interpersonal relationship in institutional residence is essential because the place is not only as both a care and a protection places for older adults, but also as older adults' gathered places, so it is the right place to develop older adults' interpersonal relationship.

There are several studies discuss significance roles of older adults' interpersonal relationship for their well-being. For instance, some of the studies examined impacts of social interaction of older adults to health dimensions of their life, including a life satisfaction and emotion and a psychic health (Nussbaum, 1983; Eckels, Hatfield, \& Traupmann, 1992; Ericsson, Holmen, \& Winbald, 1994). Another study, for instance, described older adults acknowledgment about the impacts of communicating with either friends or a family to their quality of life (Farquhar, 1995).

There are also several studies discuss older adults' interpersonal relationship in institutional residence specifically. These studies, for instance, can be categorized generally into three groups due to their points of analysis. First, studies that elaborated benefits of older adults' interpersonal relationship in institutional residence such as cooperative situations and moral supports between older adults (Powers, 1998) and able to improve an older adult's quality of life generally (Oleson et al., 1998). Second, studies that described forms of social interaction between older adults in institutional residence such as collaborations and a mutual benefit interactions (Williams \& Roberts, 1995); whereas, not entirely forms are associative, there are also forms that dissociative such as disputes and unfriendliness (Reed \& Payton, 1997). Third, study that described common conversations between older adults in institutional residence such as jokes and conversations about experiences, activities in institutional residence, and, which most talked about, their feeling during lived in institutional residence (Gutheil, 1991).

Those three groups of studies did not explore the ways to stimulate associative social interaction of older adults in institutional residence. Whereas, those ways are meaningful due to both older adults' body and mental functions have degenerated, so it makes them vulnerable to interact. Studies about older adults' interpersonal relationship in institutional residence, in fact, tend to exclude older adults who have difficulties to talk due to either impairments of a body or cognitive or both (Feldt et al., 2000). Furthermore, although there are many studies about older adults who suffered dementia, there are not several of them explored the ways to increase an intensity of social interaction of older adults who suffered dementia (Cook et al., 2002). Therefore, this study aims to fill that lack, this study aims to formulize the ways to stimulate associative social interaction of older adults in institutional residence.

This study argues older adults' interpersonal relationship in institutional residence should be elaborated by contextual social interaction and persuasive strategy complementarily. This argument indicates the interpersonal relationship as a process. The ways of either social act or social contact have happened, which means social interaction, is fondation to cultivate both a deep and a solid social relation or interpersonal relationship (Blumer, 1969). As for social interaction is formed by its context (Blumer, 1969; Hubbard, Downs, \& Tester, 2001; 2003). There are three context that form social interaction of older adults in institutional residence, namely personal instruments, structure, and culture (Hubbard, Downs, \& Tester, 2003); then, by understanding the process of social interaction was formed, can be formulized persuasive strategy to stimulate associative social interaction of older adults in institutional residence - it also can culminate to an increase of quality of interpersonal relationship. 


\section{Methodology}

This study uses a qualitative approach and conducted a case study at Jiwa Baru social protection residence, Garut, Indonesia. This study discusses the dynamic of older adults' interpersonal relationship in institutional residence. As for this study aims to formulize the ways to stimulate associative social interaction of older adults in institutional residence. In order to achieve that aim, it is vital to elaborate the interpersonal relationship as a process. This study uses a qualitative approach because its characteristics, e.g. interpretative-naturalistic, relevan with this study's substance needs that is to elaborate a depth understanding of a process. A case study as a part of qualitative approach was used because the data collection was done on a certain location and activity. The reason of Jiwa Baru social protection residence as a site of case study because it has a long history as institutional residence, the site has contributed to enhance older adults' well-being since 1921.

This study's data collection was done with in-depth and brief interviews, observation, a documents exploration, and literature review; then, the collected data was processed with thematic technique and it was validated with triangulation technique. In-depth interview was done at four people of the site's resident, namely one supervisor, two care assistants, and one older adult. All the interviews were done with Indonesian, but all citations of the interviews that written in this study were translated literally into English by the author. As for brief interview was done because the author visited the site several times with a short duration. This study's data collection process was conducted during the third quarter of 2017.

\section{The Site: Jiwa Baru Social Protection Residence, Garut, Indonesia}

Jiwa Baru Social Protection Residence was founded in 1921. Its earliest name was Garut Social Protection Residence. Garut Social Protection Residence was not only accommodated by older adults, but also homeless people, beggars, and disabled people and its had capacity only for 20 people. In 1950 , as a consequence of social-political tragedy, Garut social protection residence had changed function to accommodate the victims of that social-political tragedy and known as the poor residence. However, two years later, Garut social residence has started to accommodate older adults particularly. Jiwa Baru as the social protection residence's name was inaugurated in 1997. Now, Jiwa Baru social protection residence, which is located at RSU dr. Slamet 9B street, Garut, Indonesia, has a land area of $8120 \mathrm{~m}^{2}$ and a building area of $2096,70 \mathrm{~m}^{2}$. Its capacity has increased considerably compared to the early years, now its accommodate up to around 100 people. Its existing facilities such as an office, a hall, a mosque, a hostel, toilets, counseling rooms, medical and therapy rooms, official residences, skill centre, a kitchen, a storage room, canteens, sports centre, and a vegetable garden.

All services in Jiwa Baru social protection residence is reflect to Indonesian Law No. 13/1998 about Older Adults Social Welfare, the law has purpose to fulfill older adults' rights through public services and a social protection for neglected older adults. Existing services in Jiwa Baru social protection residence such as 1) primary needs fulfillment, 2) an accessible facilities and infrastructure, 3) medical needs fulfillment, 4) physical, social, mental, and spiritual needs fulfillment, 5) empowerment, 6) protection, and 7) socialization and coordination. Older adults in Jiwa Baru social protection residence must undertake five stages, namely 1) the first approach stage such as first contact, contract, registration, assesment, and placement for services, 2) the services implementation, 3) the resocialization, 4) the monitoring and evaluation, and 5) the termination.

Several studies in Indonesia that written in English tend to equate "social protection residence" with "elderly care" or "nursing homes" as a term. The term that written in this study "social protection residence" is refer to "rumah perlindungan sosial tresna werdha (RPSTW)" in Indonesian terms. As far as the author's knowledge, there has not been consensus in Indonesia for RPSTW in English terms yet. However, although all of them are parts of institutional residence (for older adults), in the author's opinion, RPSTW is a different concept with all types of residential care such as elderly care, eldercare, aged care, adult day care, long term care, nursing homes, assisted living facility, or sheltered housing where more exist in Europe and US. 
There are two main characteristics that differentiate RPSTW and residential care as a concept. First, RPSTW is a public service from either social ministry or region social service bureau in Indonesia; whereas, residential care has already been established as market in Europe and US, so tend to own by a private sector-if owned by a public sector, usually the term is added "public". Second, older adults in $R P S T W$ commonly have social problems as a primary problem such as neglected older adults; whereas, older adults in residential care commonly have health problems as a primary problem. So, unlike several studies in Indonesia, the author chooses to use RPSTW in English terms by translated the term literally, namely social protection residence (for older adults).

\section{Contextual Social Interaction in Institutional Residence}

Both forms and types of social interaction, ways to do interactions, or topics of conversations cannot detach from its context. Social interaction is formed by its context (Blumer, 1969; Hubbard, Downs, \& Tester, 2001; 2003). Specifically in institutional residence, the role of context to form social interaction becomes significant due to its institutional functions that are capable to influence behavior and individual development-especially to a subject who being targeted. For instance, social protection residence as a care places, as a protection places, as a resocialization places, or as an empowerment places is capable to influence both older adults' behavior and development. Therefore, context is something that should be acknowledged to understand social interaction of older adults in institutional residence. There are three context that form social interaction of older adults in institutional residence, namely personal instruments, structure, and culture (Hubbard, Downs, \& Tester, 2003).

\section{Personal Instruments}

Personal instruments are individual body parts that to be vital tools for a people to do interactions such as a mouth, ears, a body movement, or both cognitive and psychic organs. Personal instruments seem to be a weakness for older adults to do interactions in many cases due to aging, so their both body and mental functions have degenerated (Hubbard, Downs, \& Tester, 2003). The decrease of sensory system function, e.g. sight or hearing, obviously have impacts for older adults to do interactions; as well as the decrease of saraf system fuction; as well as the decrease of life motivation or loneliness due to the difference of era. The point is aging clearly capable to have impacts to social interaction of older adults. Social interaction is not only contain communication between subjects, but also it involves individual body parts that are allowed it to happen - and this is an important thing in the case of older adults.

In Jiwa Baru social protection residence, some older adults have a personal instruments problem that make them have difficulties to do interactions. The problem was identified during the first approach stage. This stage is the first meeting between the supervisor, the care assistant, and the older adult along with the family (if still have one) as the potential resident. This stage has purpose to understand and identify older adult's problems in order to him or her able to get appropriate services throughout his or her life in the residence. All older adults in Jiwa Baru social protection residence who have a personal instruments problem generally caused by speech impairment, hearing loss, sight loss, and cognitive impairment.

The first approach stage is vital because it is always helped to identify both older adults'
physical and psychological health circumstances before begin their life as residents. So,
we [the management of Jiwa Baru social protection residence] can provide appropriate
sevices ... in the case of interactions, some older adults have a body parts problem such
as a mouth, ears, and eyes that are not healthy, so when they was brought to here [Jiwa
Baru social protection residence] they already did not talk clearly (in-depth interview
with the supervisor).

Jiwa Baru social protection residence provides an assistance and a care service that suitable for every older adult who have a personal instruments problem in order to cope with the problem. These services such as an intensive assistant to assist the older adults to undertake their daily activities, provide 
helping tools for the older adults to do interactions such as hearing aid, therapy, and nonverbal communication training-which is a training to communicate without words or speech, yet using gestures to symbolize meaning.

For us [all workers of Jiwa Baru social protection residence], the key to deal with older adults' physical difficulties in order to do interactions are an intesive monitoring, making adjustments to the ways of communication such as nonverbal communication, and therapy to cope with a physical problem (in-depth interview with the care assistant $1)$.

Nevertheless, there was a moment when a personal instruments problem had severe. For instance, there was an older adult in Jiwa Baru social protection residence who suffered both severe impairments of parts of a body and cognitive, so it had made any services that were provided to help the older adult in order to do interactions were failed. Therefore, the supervisor and the care assistant adjusted the service with build a sense of community. It means, the older adult had still included in every community activity that hopefully it would touch the older adult's emotion due to togetherness that occurred. The older adult had still included in activities such as sang together, played together, did exercise together, or watched something together. Although the older adult could not be active throughout an activity, hopefully somehow it could touch the older adult's emotion.

I think, for us [all workers of Jiwa Baru social protection residence], interaction is not only about do conversations between each other, but also importantly to be included as a part of community, so hopefully it will touch people's emotion and make them happy (in-depth interview with the care assistant 1).

\section{Structure}

Structure means systematic rules that is designed to quite determine its elements and also relations between elements. In practical, in this case, structure examples are formal rules, a hierarchy of institutional residence (all levels of workers in institutional residence and also older adults) including their relations, and a physical environment (Hubbard, Downs, \& Tester, 2003). Based on the nature of structure itself, structure indeed affects agent's behavior (indivual or collective) (Giddens, 1984). However, the affect is not totally determinant, yet it is reciprocal - especially due to the time as a factor, so agent's behavior will become a habit as a time goes by and then potentially it is able to shape the structure itself (Giddens, 1984). Therefore, structure is a context that must be acknowledged due to its power to transform behavior. In this case, when older adults started to live in institutional residence, the embededd structure such as formal rules somehow has been starting to influence their behavior.

All of formal rules that created in Jiwa Baru social protection residence were committed to older adults' development specifically. From a daily lives rule, a services rule, to a stages rule were designed for older adults' benefits. For instance, both the supervisor and the care assistant has been instructed to always encourage older adults throughout all of process that must be undertaken in Jiwa Baru social protection residence. Both the supervisor and the care assistant must acts and use words that be able to give spirit, cause happiness and laughter, and strenghten bonds between older adults as a community. This rule was designed with hope that the practices could be emulate by older adults.

We [all workers of Jiwa Baru social protection residence] realize that the older adults need to be supported by all relevant parties in here [Jiwa Baru social protection residence], all of formal rules in here were made for older adults' benefits (in-depth interview with the supervisor).

All services in here [Jiwa Baru social protection residence] were made in order to make the residents as a family. We [the care assistant and older adults] watch something together, listen to the music together, sing along, or play together. Even we [all workers of Jiwa Baru social protection residence] have been picnic together for several times to strenghten a bond as a family. Many college students also came often for a practical 
work and they give older adults some training to strenghten social bond (in-depth interview with the care assistant 2).

The physical environment in Jiwa Baru social protection residence were also built to generate harmonious atmosphere for older adults. One value that is always be emphasized regarding facilities and infrastructure is inclusiveness. All facilities are be able to use by all older adults without any exception. There are two types of facilities in Jiwa Baru social protection residence, namely special and public facilities. Special facilities such as an office, a hall, a medical room, a therapy room, counseling rooms, official residence, and a storage room. These special facilities cannot be used by older adults without approval from the supervisor or the care assistant because they are meant for a professional or an official. However, when services or activities happened in these facilities, the supervisor or the care assistant always encourages older adults to do interactions. As for public facilities such as a mosque, a hostel, toilets, skill centre, a kitchen, canteens, sports centre, and a vegetable garden. Contrary to special facilities, these public facilities are available for older adults. Older adults often spend their leisure times in these facilities and both direct and intimate interactions between them always happened in there. The management of Jiwa Baru social protection residence was aware that the existance of public facilities would be helped to increase older adults' a solid and a deep social relation due to leisure times activities.

Public facilities were built for older adults to spend their leisure times ... in there, many older adults love to plant vegetables or play in the sports centre or cook together in the kitchen. They always laugh and look happy in there. I am also happy to see them in there (in-depth interview with the care assistant 1).

Unfortunately, the supervisor and the care assistant have worried about two problems regarding structure as a context. First, an issue of relationship with older adults' family (if still have one). Jiwa Baru social protection residence has not been created a formal rule to communicate with the family in regularly yet. Most families tended to come to the residence only at the first approach stage, afterward, it just a few families. This has been a problem because it affected a psychological condition of older adults, they tended to feel excluded by the family. The supervisor and the care assistant has been also unable to monitor and evaluate older adults appropriately that involved the family. Whereas, if older adults will go forth from Jiwa Baru social protection residence, it was targeted that they will be ready to live without an intensive assistant. Second, an issue of provision of helping tools for older adults to do interactions such as hearing aid. This issue has happened due to the lack of helping tools. "There is not enough budget for that," said the supervisor during in-depth interview.

\section{Culture}

Culture in this case refers to values, perceptions, or customs that exist in institutional residence (Hubbard, Downs, \& Tester, 2003). In practical, the examples are values or philosophy of institutional residence in terms of provide services for older adults, perceptions about older adults as a signifier among the residents, or informal routine behaviors in institutional residence (Hubbard, Downs, \& Tester, 2003). Culture in institutional residence shapes social interaction in a complex way. It does not have both direct and coercive roles, but it becomes crucial to develop associative social interaction (Hubbard, Downs, \& Tester, 2003). For instance, it seems difficult to describe the effects of tolerance or emphaty as a value in institutional residence, yet both of them are vital to be applied in daily activities.

In Jiwa Baru social protection residence, there were difference perceptions among older adults that often prevent associative social interaction happened. There was a bad perception to older adults who suffered mental illness, so they were tended to be excluded. The supervisor and the care assistant had ways to dispel that perception with doctrine, ideology, and a cultural value. The care assistant elevated both tolerance and emphaty as a value to older adults during social and spiritual needs fulfillment. In social needs fulfillment, there are a consultation session and a social guidance session. During both of sessions, the care assistant specifically explained the importance of an inclusive community-people should not discriminate each other because social bonds would give a lot of benefits such as 
collaborations and moral supports. As for in spiritual needs fulfillment, there is a religious session. During this session, the care assistant specifically explained the importance of respected each other because all people are created by God and equal in God's sight.

I terrified to get close to someone who suffered mental illness. He [the older adult who suffered mental illness in Jiwa Baru social protection residence] liked to be angry and screamed so loudly while there is nothing. Really a vague people. I preferred to stay away from him, I was terrify (in-depth interview with the older adults).

There are some special customs in Jiwa Baru social protection residence. The supervisor and the care assistant have special greetings or rituals before conducting activities. These to be expected able to strenghten social bonds between older adults as a community. As for there was an effort to replicate structure into culture. It means, a formal rule was changed into a habit. The supervisor and the care assistant thought this way would reduce the burden of doing an activity because there is no coercion in it. It means, in a habit, people doing an activity self-consciously. For instance, in the early times of a vegetable garden existance, nobody older adults went to there. Afterwards, the care assistant has been instructed to do a lot of activities in a vegetable garden. Therefore, now older adults often spend their leisure times in a vegetable garden and both direct and intimate interactions between them always happened. Some of them even love to plant and manage vegetables. The management of Jiwa Baru social protection residence was aware that the existance of a vegetable garden would not only helped to improve interactions between older adults, but also their skills, cognitive, and cooperations between older adults.

... yes, first, we [the supervisor and the care assistant] made the rule [a vegetable garden's rule]. At least older adults should be told first. Afterwards, as a time goes by, a rule changed into a habit for older adults, now they go to vegetable garden selfconsciously. There is no coercion in it. They spend their leisure times in a vegetable garden. Now older adults has been instructed to always smile when passed other people in here. We hope this rule also can be a habit for older adults at sometime in the future (in-depth interview with the care assistant 1).

\section{Persuasive Strategy: The Ways to Stimulate Associative Social Interaction}

Previous part has analyzed the "why" social interactions of older adults in institutional residence can be formed; then, by understanding that, this part shows the "how to" stimulate associative social interactions of older adults in institutional residence-it also can culminate to the increase of interpersonal relationship quality. This part, exploring the "how to", is vital due to both older adults" body and mental functions have degenerated, so it makes them vulnerable to interact. Although older adults has already gathered in institutional residence, they still tend to have difficulties to do interactions because sensory impairments or personal reasons such as they prefer to be alone (Vargheese et al., 2013). Therefore, there is persuasive strategy. It means, both subtle and non-coercive ways to stimulate associative social interaction of older adults (Vargheese et al., 2013). There are four persuasive strategy based on the formed of social interaction of older adults in Jiwa Baru social protections residence, namely persuaded by a closest friend, provide both a suitable assistance and care, create an interactive culture, and build a sense of community.

Persuaded by a closest friend is the easiest way to implement persuasive strategy. A closest friend is capable to make us feel happy, comfort, calm, and enjoyment, capable to help us to cope with problems and traumas, capable to encourage us to do something positive, and capable to improve our selfconfidence and self-worth. In Jiwa Baru social protection residence, there are a physical environment and activities that are potentially helped older adults to have a closest friend. For instance, public facilities in Jiwa Baru social protection residence, such as vegetable garden or kitchen, are available for older adults to spend their leisure times, so they can do both direct and intimate interactions between each other in there. This advantege situation must be utilized by the management of Jiwa Baru social protection residence to recognize older adults' closest friend, so associative social interaction can be 
stimulated through the closest friend. If there is an older adult who do not want to involve in community activities, the care assistant can ask help to the closest friend in order to persuade the older adult. If there is also an older adult who have difficulties to do interactions, the care assistant can ask help to the closest friend in order to encourage the older adult. Support from a closest friend definitely has more meaning for older adults. The management of institutional residence can do a Sociometry method to identify the closeness of older adults. Sociometry is a method to explore socio-emotional networks of relationship in a group or a community.

Provide both special assistance and care are indispensable to stimulate associative social interaction for older adults who have a personal instruments problem. Jiwa Baru social protection residence has a stage to identify older adults' problems, including their personal instruments problem. This stage's purpose is to understand and identify an older adult's problems in order to him or her able to get appropriate services when became a resident. Provide services based on a specific older adults' needs is crucial to develop their well-being. Jiwa Baru social protection residence provides both special assistance and care for older adults who have a personal instruments problem to stimulate associative social interaction, such as an intensive assistant, helping tools, therapy, and nonverbal communication training.
... [an intensive assistant refers to] always accompany him [the needy older adult] throughout every activity, it is like always alongside him. Even if we [the care assistant and the older adult] sang together or did exercise every morning, for example, he has always been included and I have accompanied him. He may not be active throughout an activity, but he always be included. ... my role is to give an assistance for him to undertake daily activities and accompany him throughout every community activity. He may not be active, but the important thing is he can feel the togetherness as a community (in-depth interview with the care assistant 2).

Another way to stimulate associative social interaction is create an interactive culture. It means, in this case, develop a habit or a perception to older adults in order for they do not have difficulties to do interactions. All of older adults should have social interaction, regardless they have a personal instruments problem or not. For the sake of older adults who have a personal instruments problem, Jiwa Baru social protection residence provides helping tools and nonverbal communication training. Both of them are important to older adults who have a personal instruments problem to do interactions; the good thing is they are not abandoned, there is an inclusive culture, they still can do interactions. Furthermore, if there is a bad perception among older adults that prevents them to do interactions, Jiwa Baru social protection residence elevates both tolerance and emphaty as a value to older adults during both social and spiritual needs fulfillment. During social needs fulfillment, older adults are explained about the importance of an inclusive community - people should not discriminate each other because social bonds will give a lot of benefits such as collaborations and moral supports. As for during spiritual needs fulfillment, older adults are explained about the importance of respected each other because all of people are created by God and equal in God's sight. Other way to create an interactive culture such as communicate with writing or pictures. The management of institutional residence can show pictures of the togetherness as a community to older adults in order to promote social bonds.

The last of persuasive strategy in this case is build a sense of community. Older adults should always be included in every community activity, never ever exclude them. The important thing is older adults can feel the togetherness as a community; then, at some point, older adults can feel comfort to do interactions. Jiwa Baru social protection residence always emphasizes the importance of a community to older adults, even to older adults who suffered both severe impairments of parts of a body and cognitive, so it makes them have an arduous situation to do interactions. Jiwa Baru social protection residence always include them in every community activity in order for hopefully the togetherness that occured can touch their emotion. Although they may not be active throughout an acitivity, once again, the important thing is older adults can feel the togetherness as a community. The care assistant in Jiwa Baru social protection residence acknowledges this thing, she said, “... interactions is not only about do conversations between each other, but also importantly to be included as a part of community, so hopefully it will touch people's emotion and make them happy." Finally, build a sense of community is 
the one thing that fundamental to stimulate associative social interaction. Other institutional residence should identify a relevant way to build a sense of community.

\section{Conclusion}

Interpersonal relationship is not something that be a given, it is a process, especially for older adults that vulnerable to interact. Therefore, it should be elaborated by contextual social interaction and persuasive strategy complementarily. There are three context that form social interactions of older adults in institutional residence, namely personal instruments, structure, and culture; then, by understanding the process of social interaction was formed, can be formulized persuasive strategy to stimulate associative social interactions of older adults in institutional residence-it also can culminate to an increase of quality of interpersonal relationship. A social worker should be able to identify a suitable persuasive strategy, and then implement it, in order for institutional residence works effectively as a place to develop older adults' interpersonal relationship and well-being. This study recommends other future similar study to examine the impact of persuasive strategy that is undertaken by institutional residence to either an intensity of associative social interaction or a quality of interpersonal relationship of older adults with quantitative approach. That study also can conduct a longitudinal method, regarding to durations as a essential factor for persuasive strategy to work functionally.

\section{References}

Berscheid, E. (1999). The Greening of Relationship Science. The American Psychologist, 54, 4, 260266.

Blumer, H. (1969). Symbolic Interactionism: Perspective and Method. New Jersey: Prentice Hall.

Central Bureau of Statistics of Indonesia. (2017). Statistik Penduduk Lanjut Usia 2017. Jakarta: Badan Pusat Statistik.

Cook et al. (2002). Beyond Words: Older People with Dementia Using and Interpreting Nonverbal Behaviour. Journal of Aging Studies, 16, 3, 155-167.

Eckels, E., Hatfield, E., \& Traupmann, J. (1992). Intimacy in Older Women's Lives. The Gerontologist, 22, 6, 493-498.

Ericsson, K., Holmen, K., \& Winbald, B. (1994). Loneliness and Living Conditions of the Oldest Old . Scandinavian Journal of Social Medicine, 22, 1, 15-19.

Farquhar, M. (1995). Elderly People's Definitions of Quality of Life . Social Science and Medicine, $41,10,1439-1446$.

Feldt et al. (2000). The Relationship between Social Interaction and Characteristics of Aggressive, Cognitively Impaired Nursing Home Residents. American Journal of Alzheimer's Disease, 15, $1,10-17$.

Giddens, A. (1984). The Constitution of Society: Outline of the Theory of Structuration. California: University of California Press.

Gutheil, I. (1991). Intimacy in Nursing Home Friendships. Journal of Gerontological Social Work, 17, $1 / 2,59-73$.

Hubbard, G., Downs, M. G., \& Tester, S. (2001). Including the Perspectives of Older People in Institutional Care during the Consent Process. In H. I. Wilkinson, The Perspectives of People with Dementia (pp. 63-82). London: Jessica Kingsley.

Hubbard, G., Downs, M. G., \& Tester, S. (2003). Meaningful Social Interactions between Older People in Institutional Care Settings. Ageing and Society, 23, 99-114.

Ministry of Health of Indonesia. (2017). Lansia di Indonesia. Jakarta: Pusat Data dan Informasi Kementrian Kesehatan Republik Indonesia.

Nussbaum, J. F. (1983). Relational Closeness of Elderly Interaction: The Implications for Life. Western Journal of Speech Communication, 47, 229-243.

Oleson et al. (1998). Improving nursing home quality of life : residents helping residents. American Journal of Alzheimer's Disease, 138-146. 
Powers, B. (1988). Social Networks, Social Support, and Elderly Institutionalized People. Advanced Nursing Science, 10, 2, 40-58.

Reed, J., \& Payton, V. R. (1997). Understanding the Dynamic of Life in Care Homes for Older People: The Implications for De-institutionalizing Practice. Health and Social Care in the Community, 5, 4, 261-268.

Vargheese et al. (2013). Persuasive Dialogue for Older Adults: Promoting and Encouraging Social Interaction. CHI, Changing Perspectives (pp. 877-882). Paris: CHI.

Williams, B., \& Roberts, P. (1995). Friends in Passing: Social Interaction at an Adult Day Care Center. International Journal of Aging and Human Development, 41, 1, 63-78. 